\title{
Deformation-induced orientation spread in individual bulk grains of an interstitial-free
} steel

Oddershede, Jette; Wright, J.P.; Beaudoin, A. ; Winther, Grethe

\section{Published in:}

Acta Materialia

Link to article, DOI:

10.1016/j.actamat.2014.11.038

Publication date:

2015

Document Version

Peer reviewed version

Link back to DTU Orbit

Citation (APA):

Oddershede, J., Wright, J. P., Beaudoin, A., \& Winther, G. (2015). Deformation-induced orientation spread in individual bulk grains of an interstitial-free steel. Acta Materialia, 85, 301-313.

https://doi.org/10.1016/i.actamat.2014.11.038

\section{General rights}

Copyright and moral rights for the publications made accessible in the public portal are retained by the authors and/or other copyright owners and it is a condition of accessing publications that users recognise and abide by the legal requirements associated with these rights.

- Users may download and print one copy of any publication from the public portal for the purpose of private study or research.

- You may not further distribute the material or use it for any profit-making activity or commercial gain

- You may freely distribute the URL identifying the publication in the public portal 


\title{
Deformation-induced orientation spread in individual bulk grains of an interstitial-free steel
}

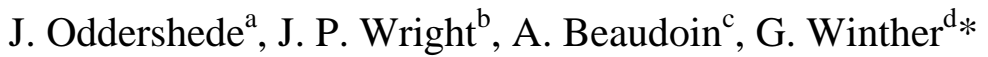 \\ ${ }^{a}$ Department of Physics, Technical University of Denmark, DK-2800 Kgs. Lyngby, Denmark \\ ${ }^{b}$ European Synchrotron Radiation Facility, 38043 Grenoble, France \\ ${ }^{c}$ Department of Mechanical Science and Engineering, University of Illinois at Urbana-Champaign, \\ Champaign, IL, USA \\ ${ }^{d}$ Department of Mechanical Engineering, Technical University of Denmark, DK-2800 Kgs. Lyngby,
} Denmark

\begin{abstract}
Three-dimensional X-ray diffraction has been employed to characterise the lattice rotations of individual bulk grains in a $9 \%$ tensile deformed sample of interstitial-free steel. Three grains of initially close orientation that are representative of the scatter of all investigated grains with tensile axes near $\langle 522\rangle$ have been identified. Their rotation paths and intragranular orientation spread have been analysed in detail, using crystal plasticity modelling to evaluate the nature of the orientation spread. It is found that the same set of most stressed slip systems are active in the three grains and that variations in the relative activities of the two most stressed systems account for the dominant orientation spread in the grains. The distribution of slip on these systems varies from grain to grain and also within each grain. While the grain orientation controls the identity of these slip systems, the variations are attributed to grain boundary and grain interaction effects.
\end{abstract}

Keywords: Ferritic steels; Tensile behaviour; High-energy X-ray diffraction; Individual bulk grains; Crystal plasticity

\section{Introduction}

Thermo-mechanical processing of polycrystalline metals has been a subject of research for almost a century. The field has been significantly advanced through the development of novel experimental techniques, giving crystallographic information at the level of individual grains, such as electron microscopy in 2D [1,2] and lately high-energy X-ray diffraction at synchrotrons in 3D [3,4]. Threedimensional X-ray diffraction (3DXRD) using synchrotron radiation is capable of characterizing individual grains embedded in the bulk of a polycrystalline metal. As the technique is nondestructive it enables studies of the same set of bulk grains before and after some external stimuli, e.g. elastic [5-7] and plastic deformation [8-11] or thermal annealing [12-14]. Several experimental set-ups are possible, each with specific advantages, e.g. high temporal resolution $[12,15]$, high spatial resolution of grain maps [11,16] or high resolution of crystallographic orientations $[17,18]$.

In parallel, polycrystal plasticity models have evolved from the classical Sachs [19] and Taylor/Bishop-Hill models [20,21] based primarily on the crystallographic orientation of the grains to increasingly complex models accounting for interactions between clusters of grains [22,23], interactions between a grain and a matrix representing the average of the other grains [24] and finite-element-based models accounting for the detailed interaction between neighbouring grains [25-27] as well af FFT-based methods [28]. The different behaviour of grains with initially similar 
orientations as well as the evolution of intragranular orientation differences during plastic deformation are currently key topics studied. The critical scientific questions are to what extent the behaviour of the grain is controlled by its crystallographic orientation, and which role the interaction with the neighbouring grains plays. Assessment of the former is important for advancing constitutive relations for slip.

The present paper addresses this subject by investigating the intergranular variations in lattice rotations and the active slip systems for selected grains of a specific initial orientation, as well as the intragranular slip system differences leading to orientation gradients across these grains. The grains selected for such studies should of course be representative of the ensemble of grains of that particular orientation and the experimental basis is therefore a 3DXRD set-up optimized for characterization of a large number of grains in a tensile-deformed IF-steel with a fairly strong rolling texture. From this data set representative grains are then identified for detailed studies.

In the 3DXRD experiment each grain gives rise to a number of diffraction spots, and the evolution of these is tracked as the sample is deformed. As the grain rotates the diffraction spots move and at the same time they broaden due to the evolving intragranular orientation spread. The method employed here is to index the individual reflections to determine an average (centre-of-mass (CMS)) orientation of each individual grain before deformation and after $9 \%$ elongation. The rotation paths of about a hundred grains are analysed and three representative grains with initial tensile axes near <522> are selected for the detailed analysis. The active slip systems of these grains are identified by crystal plasticity analysis and the intragranular slip system variations causing the orientation spread within each of the three grains are also investigated by crystal plasticity simulations. The simulated orientation spread is converted to simulated diffraction spots, the shape of which is then compared to the experimental reflections.

\section{3DXRD experiment and grain reconstruction}

The material selected for the study was a fully recrystallised interstitial-free steel $(99.6 \mathrm{wt} \% \mathrm{Fe})$ with a well-developed body-centred cubic rolling texture and grains with average dimensions of $50 \times 50 \times 70 \mu^{3}$. A tensile sample with a square cross section of $0.7 \times 0.7 \mathrm{~mm}$ and a length of $30 \mathrm{~mm}$ was machined by spark cutting, i.e. with about 200 grains in the cross section. Consecutive layers perpendicular to the tensile axis of the sample were mapped by 3DXRD in the undeformed state with a beam height of $10 \mu \mathrm{m}$. Subsequently the sample was tensile deformed ex situ to first 3\%, then $6 \%$ and finally $9 \%$ elongation. When positioning the sample in the stress rig as well as in the 3DXRD set-up for mapping between tensile steps, extreme care was taken to align the tensile axis in the same way, using the entire sample length of $30 \mathrm{~mm}$ as a guideline. Due to the combination of the strong texture of the sample, the number of grains in the cross section and the deformationinduced intragranular orientation spread, peak overlap in the 3DXRD data became severe after 6\% elongation. To reduce the number of grains in the cross section, and thereby the peak overlap after 9\% deformation, the sample was mechanically polished to about half of the original dimensions of the cross section. For the polished sample 60 layers with an interlayer spacing of $20 \mu \mathrm{m}$ were mapped with a beam height of $10 \mu \mathrm{m}$. Note that as the polishing was done after the final deformation step all investigated grains were bulk grains far from the free sample surface as far as the tensile deformation is concerned. 


\subsection{DXRD set-up and analysis}

The 3DXRD experiment was performed at beamline ID11 at the European Synchrotron Radiation Facility. Two detectors were used simultaneously: 1) A Quantix near-field detector with $1536 \times 1024$ pixels of dimensions $4.3 \times 4.3 \mu^{2}$ placed at a sample-to-detector distance of $9.3 \mathrm{~mm}$, and 2) A Frelon4M far-field detector [29] with $2048 \times 2048$ pixels of $50 \times 50 \mu \mathrm{m}^{2}$ placed at a distance of 195 $\mathrm{mm}$, see Figure 1 for a schematic of the set-up. The X-ray energy was $69.5085 \mathrm{keV}$ (W edge); the beam was monochromated using a bent Laue monochromator which also provided vertical focusing to $10 \mu \mathrm{m}$, while a slit was used to confine the horizontal beam dimension to $1.5 \mathrm{~mm}$. The planar beam was used to map the sample layer-by-layer. For each layer the sample was rotated around the tensile axis, acquiring diffraction images for $\omega$-angles in the range of $\left[-22.5^{\circ} ; 22.5^{\circ}\right] \cup\left[67.5^{\circ} ; 112.5^{\circ}\right]$ in steps of $0.5^{\circ}$.

The FABLE software [30] was used to identify the individual grains within the sample from the diffraction reflections. The philosophy was to use the far-field data to index the reflections coming from individual grains (i.e. determine their crystallographic orientations), and get a rough estimate of their positions within the sample, while the near-field data were used to improve the spatial resolution. The indexing was performed using GrainSpotter [31]. For the subsequent refinement against both near- and far-field data the FitAllB module [32] was applied. Due to extensive reflection overlap in the 3DXRD data for the $6 \%$ elongated sample, only the data after strains of 0 , 3 and $9 \%$ were reconstructed. In the present context we focus on analysing the structure after $9 \%$ deformation.

\subsection{Reconstruction of grains}

Because the beam height $(10 \mu \mathrm{m})$ was substantially less than the average grain size along the tensile direction $(70 \mu \mathrm{m})$ the grains could be observed in several subsequent layers. The matching of grain segments identified in consecutive layers was carried out using the average grain diameter in the cross section $(50 \mu \mathrm{m})$ as a distance criterion and a misorientation criterion of $3^{\circ}$ at all strains. These matching criteria are essentially the same as those used by Nervo et al [33] in a comparative study of near- and far-field experiments. The matching of such grains from one deformation level to the next was then performed using a distance criterion of $50 \mu \mathrm{m}$ in the $x y$-plane perpendicular to the tensile axis and a total of $100 \mu \mathrm{m}$ in all three dimensions to account for potential errors originating from not having identified all segments of a grain, which may shift the centre-of-mass position somewhat along the tensile axis. The misorientation criteria used to match grains observed at different strain levels were $3^{\circ}$ from $0 \%$ to $3 \%$ and $6^{\circ}$ from $3 \%$ to $9 \%$ deformation. In the matching process the only grain observed with the tensile axis along $\langle 100\rangle$ was used as a marker serving as a reference position at all strain levels, and an overall rigid body translation of the sample was applied to minimise the distance between matched grain positions before and after deformation.

In this way about half of the grains (i.e. a total of 107 grains) in the investigated $0.35 \times 0.35 \times 1.2 \mathrm{~mm}^{3}$ sample volume after $9 \%$ elongation could be followed all the way to $9 \%$. Figure 2 shows the threedimensional map of the spatial positions of these 107 grains from two viewing positions. The initial positions of the grains in the undeformed state are marked by open circles and their corresponding final positions after $9 \%$ elongation by filled circles. The grain displacements along the $\mathrm{z}$-axis after deformation are consistent with a $9 \%$ elongation of the sample. As seen from the top-view in Figure $2 b$ the grains on average move towards the sample centre upon deformation in agreement with the 
expected contraction perpendicular to the tensile axis. This also demonstrates that the sample is not rotated between the two maps.

Figure 3a shows the lattice rotations of the 107 grains, where the filled symbols mark the final orientation after $9 \%$ elongation. The lattice rotations in Figure $3 \mathrm{a}$ resemble corresponding data previously published for $6 \%$ tensile elongated aluminium $[9,10]$, except that the rotation directions are opposite - as expected when going from face-centred to body-centred cubic metals. The grains near the [001] $-[\overline{1} 11]$ line rotate towards [001], but with significant scatter. The grains in the middle of the triangle and close to $\langle 110\rangle$ rotate towards $\langle 110\rangle$.

\section{Selection of grains and reflections}

The aim of the present study is to conduct a detailed investigation of initially similarly oriented grains. Grains initially close to the $\langle 522\rangle$ orientation at the midpoint of the [001] $-[111]$ line are selected because they exhibit substantial scatter in the rotation directions with components towards and away from the [001] - [111] line, where the Taylor model predicts rotations parallel to this line. This behaviour is in full agreement with previous observation of similarly oriented grains in aluminium [10]. The interest in this particular orientation is further enhanced by the fact that in this part of the stereographic triangle the rotation of the tensile axis is remarkably unaffected by the socalled Taylor ambiguity [34], i.e. according to the model the tensile axes of all the grains should follow the same rotation path.

In the following three representative grains are identified. For each of these, three reflections are selected for subsequent comparison with simulated reflections to identify the nature of the orientation spread.

\subsection{Selection of grains}

The basic criteria for selection of the three grains were 1) that they represent the observed differences in rotation behaviour for grains of that orientation, 2) that they were well-resolved from other grains both in the initial undeformed sample and also in the polished sample after $9 \%$ deformation, and 3) that a sufficient number of reflections must be identified in several consecutive layers to cover a representative grain volume. The last point is easily fulfilled in the undeformed sample but becomes more critical after $9 \%$ deformation. The three grains selected (labelled A, B and C) have more than 20 reflections identified in at least three consecutive layers, i.e. each grain is well-characterised over at least $50 \mu \mathrm{m}$ along the sample height. The initial orientation of the three grains selected and their CMS rotations during 9\% deformation are marked in Figure 3. It is seen in Figure 3a that the tensile axes of all three grains rotate closer to [001], in agreement with the rest of the grains in that part of the triangle. Grains $\mathrm{A}$ and $\mathrm{C}$ also have rotation components towards the [001] - [111] line whereas grain B rotates away from this line. Further the magnitudes of the rotations are different, with grain A rotating the least and grain B the most. When compared to the other grains of similar orientation, the three selected grains represent the observed rotation differences well. For completeness Figure $3 b$ illustrates that the full orientations and not just the tensile axes of the three grains are very close due to the strong body-centred cubic rolling texture. The largest misorientation between any of the three grains is $12^{\circ}$. The three grains rotate in the same direction around the tensile axis, and grain A exhibits the smallest rotation as is also the case for the tensile axis. 


\subsection{Selection and graphic presentation of reflections}

The problem of investigating the orientation spread based on the shape changes of diffraction spots is somewhat analogous to inspection of the spread of a single pole in a pole figure: depending on the nature of the orientation spread some reflections will change only little while others may elongate significantly in directions which will vary from reflection to reflection. For this reason several reflections should be included and these should be carefully selected to be as well-resolved from other reflections and as distinct as possible.

For each grain three representative reflections measured at the central layer of the corresponding grain after $9 \%$ deformation were selected for the analysis. The reflection coordinates $(2 \theta, \eta, \omega)$ refer to the scattering angle $2 \theta$ (radial direction on the detector), the azimuthal position $\eta$ on the detector, and the rotation angle $\omega$ of the sample, see Figure 1 for reference. The reflections were selected based on the following criteria: 1$)$ no peak overlap is tolerated along any of the coordinates $(2 \theta, \eta$, $\omega)$, 2) the reflections should be in the interior of the collected $\omega$-intervals in order to avoid premature cut-off at the edges of the scan ranges, 3) reflections close to the pole, i.e. within $10^{\circ}$ of either $\eta=0^{\circ}$ (up along the rotation axis) or $\eta=180^{\circ}$, are not considered as these tend to stretch very far in $\omega$, and 4) reflections on different Debye-Scherrer rings, i.e. with different values of $2 \theta$ and Miller indices (hkl) of the reflecting crystallographic planes, are preferred if such a set can be found to fit the first three criteria. Table 1 shows the specifications of the set of selected reflections.

The broadening of the reflections occurs in three dimensions, i.e. along the azimuthal angle $\eta$ and the radial direction $2 \theta$ on the detector image as well as in the direction of the $\omega$ rotation angle. The broadening in $\omega$ means that the reflection is present in several detector images. The broadening in $2 \theta$ is due to the physical dimensions of the grain itself as well as elastic strain distributions. It is by far the smallest of the three in the present case, and it was therefore decided to ignore this contribution by integrating each reflection over the $2 \theta$ coordinate and showing the spread as a function of $\eta$ and $\omega$ only (see Figure 4 for examples). The alternative, integrating over $\omega$ and showing the spread as a function of the pixel coordinates on the detector, is a more direct representation of the measured data, but has the disadvantage that the shape of the predominant spread along $\eta$ becomes a function of the position of the spot on the detector. Figure 4 shows an example of diffraction spots for grain A (a) before and (b) after 9\% deformation. Please note that the intensities in the various representations of each reflection (experiment before and after deformation plus simulations) do not integrate to the same value since an arbitrary scale was chosen for best viewing in each case.

\subsection{Comparison with modelling results}

The orientation spread of grains A, B and C is modelled in subsequent sections. In order to compare the simulated orientation spread with the experiment the FABLE polycrystal simulator, PolyXSim, was employed to provide forward projections of simulated reflections onto a virtual detector similar to the one used in the actual experiment. In the simulations the beam energy was assumed to be perfectly monochromatic, the experimentally determined spatial distortion of the detector was taken into account and a detector point spread of three pixels was added. The individual grains were modelled as a collection of grains, each located at the experimentally determined centre-of-mass position, but with different orientations determined from a crystal plasticity model. The simulated reflections from the relevant range of virtual detector images were integrated for graphic representation as described above. 


\section{Crystal plasticity analysis of intergranular variations in CMS rotation}

The aim of this section is to identify the most important slip systems in the three grains as well as the intergranular variations in the slip activities leading to the differences in rotation. Three different types of analysis are pursued. At first, the Schmid factors are analysed. The initial interest in the three selected grains arose because the Taylor model does not predict the observed CMS rotations. Nevertheless calculations with the Taylor model are included as the second approach to demonstrate which slip systems to expect based on the grain orientation only. As the third approach a previously developed method [35] based on the kinematics of slip is employed in order to determine the slip system activity which matches the observed rotations. The method is an extension of the Taylor model to consider not only the five independent strain components $\left(\varepsilon_{i j}\right)$ as input but also the three measured lattice rotation components $\left(r_{i j}\right)$. The standard set of five equations relating the strain to the shears on the individual slip systems $\left(\gamma^{k}\right)$ are therefore supplemented by three equations for the rotation (assuming that the measured lattice rotation corresponds to the rigid body rotation of the grain). The equations are

$$
\begin{aligned}
& \varepsilon_{i j}=\sum_{k=1}^{8} \gamma^{k}\left(b_{i}^{k} n_{j}^{k}+b_{j}^{k} n_{i}^{k}\right) / 2 \\
& r_{i j}=\sum_{k=1}^{8} \gamma^{k}\left(b_{i}^{k} n_{j}^{k}-b_{j}^{k} n_{i}^{k}\right) / 2
\end{aligned}
$$

with $\mathrm{b}=\left(b_{1}, b_{2}, b_{3}\right)$ and $\mathrm{n}=\left(n_{1}, n_{2}, n_{3}\right)$ being the unit vectors representing the slip direction and slip plane normal in the sample coordinate system. Only slip systems of the $\{110\}<111\rangle$ family are considered, all systems have the same critical resolved shear stress and hardening is neglected.

Eq. 1 can be solved to give eight unknown shears on the individual slip systems $\left(\gamma^{k}\right)$ for a prescribed strain tensor. Analogous to the calculations in the Taylor model, many slip system combinations will satisfy the equations, but these require different amounts of plastic work. The Taylor procedure of minimising the internal work is also adopted here, i.e. the slip system combination with $\left(\sum \gamma^{j}\right)_{\min }$ is selected. Note that ambiguity is not a problem as the solution is unique in this case.

The strain tensor employed in both the standard Taylor model and the calculations according to Eq. 1 consists of elongation along the tensile direction, a prescribed contraction and no shear components, i.e.

$$
\varepsilon=\varepsilon_{n o m} \cdot\left(\begin{array}{ccc}
-q & 0 & 0 \\
0 & -(1-q) & 0 \\
0 & 0 & 1
\end{array}\right)
$$

where $\mathrm{q}$ defines the contraction and $\varepsilon_{\text {nom }}$ is the overall $9 \%$ elongation the sample.

The contraction expected for the sample as a whole is determined by a standard Taylor calculation with variations in the Lankford parameter $\mathrm{R}=\mathrm{q} /(1-\mathrm{q})$ for an ensemble of $\sim 1300$ grain orientations indexed in the undeformed sample. The smallest Taylor factor is obtained for $\mathrm{R}=3.0$, which exceeds 
unity as expected due to the strong bcc rolling texture. However, the local values at the grain scale may deviate from this estimate of the bulk value. Finite element studies of the intergranular strain variations when changing the spatial arrangement, and thus the neighbours, of grains in an initially randomly textured sample subjected to plane strain compression to a true strain of about 1 indicate extreme strain variations of the order of $\pm 35 \%$ [36]. Another study of a moderately textured sample deformed in ECAP to a similar strain revealed variations of the order of $\pm 20 \%$ [37]. Variations of $q$ of the order of $\pm 35 \%$ from an R-value of 3 correspond to R-values of 1 and infinity (the latter being plane strain conditions). To account for such variations, calculations with $\mathrm{R}=1,3$ and $\infty$ are therefore presented in the following analysis for the three grains. Please note that calculations with corresponding variations in tensile and shear strain components were also conducted. For clarity they are not presented here as they did not contribute new insight.

\subsection{Major slip systems}

The Schmid factors calculated for uniaxial loading are listed in Table 2 for each grain. All three grains have $(0 \overline{1} \overline{1})[11 \overline{1}]$ and $(\overline{1} 01)[111]$ as the systems with the two highest Schmid factors (in the following termed primary (P) and conjugate (C) systems, although these terms are normally used with face-centred cubic crystals). These two systems have almost identical Schmid factors for grains $\mathrm{A}$ and $\mathrm{B}$, which lie closest to the [001] - [111] line, whereas the difference for grain $\mathrm{C}$ is larger. The two coplanar systems $(1 \overline{1} 0)[11 \overline{1}]$ and $(1 \overline{1} 0)[\overline{111}]$ are among the remaining systems with high Schmid factors for all three grains. These two systems are codirectional with the $\mathrm{P}$ and $\mathrm{C}$ systems, and are therefore termed CDP and CDC, respectively. Note that the difference in Schmid factors from the $\mathrm{P} / \mathrm{C}$ systems to the next ones is large, except for grain $\mathrm{C}$ where systems $\mathrm{C}$ and $\mathrm{CDP}$ have similar Schmid factors. Although the stress state of each grain may not be strictly uniaxial, as observed for e.g. hexagonal close packed metals [38], these systems are still expected to be highly stressed.

For grains $\mathrm{A}, \mathrm{B}$ and $\mathrm{C}$ with tensile axes in the stereographic triangle of Figure $3 \mathrm{~b}$, activity on systems P or CDP cause rotation from the [001]-[101] line and into the triangle, whereas systems $\mathrm{C}$ or $\mathrm{CDC}$ give rotations towards and eventually across this line. All four systems contribute substantially to the tensile elongation. Systems $\mathrm{P}$ and $\mathrm{C}$ cause contraction mainly along the $\mathrm{x}-$ direction of the sample, whereas CDP and CDC give contraction along the $y$-axis (with $\mathrm{z}$ being the tensile direction).

The slip activities calculated with the Taylor model are listed in Table 3. For clarity the activities are averaged over the three grains as they are very close in orientation and the variations between them consequently small. The two solutions to the Taylor ambiguity problem (which give practically the same rotation of the tensile axes) have also been averaged. The calculations with different $\mathrm{R}$-values show a minimum Taylor factor for $\mathrm{R}=3$, in agreement with the value obtained for the bulk texture. As seen in the table the four systems considered here account for most of the total slip with the Taylor model, irrespective of the R-value. At $\mathrm{R}=3$ the $\mathrm{P}$ and $\mathrm{C}$ systems are responsible for about $60 \%$ of the total slip.

Table 4 lists the slip system activities when taking also the measured lattice rotations for each grain as an input to the calculations. These calculations aim at elucidating the intergranular slip system variations leading to the different rotation paths for the three grains. Except for grain $B$ the minimum work is found for $\mathrm{R}=3$ as with the Taylor model and irrespective of the $\mathrm{R}$-value about 
$70 \%$ of the total slip is on the same four systems considered before, although the CDP/CDC systems sometimes have very little or no activity. The total sum of slip activities and, as a consequence, the work, is only about $20 \%$ larger when including the rotations. This may be attributed to the use of the CMS rotation of grains exhibiting intragranular orientation spread and possibly also to local strain differences.

The results of the three types of analysis conducted here unambiguously agree that the four systems considered account for the majority of the slip in the three grains, even when allowing for large variations in the strain tensor. Intergranular variations in the relative activities of these slip systems are the main reason for their different CMS rotations. The fact that the intergranular differences are consistently explained by activation of the same set of slip systems also suggests that the intragranular orientation spread is likely to be caused by variations in these systems. This hypothesis is explored in the following.

\section{Analysis of intragranular orientation spread}

The intragranular orientation spread originating from relative variations in the activities of the two most active systems ( $\mathrm{P}$ and $\mathrm{C}$ ) is evaluated based on the slip system activities determined above from the CMS rotations for $\mathrm{R}=3$ (see Table 4). This value was selected as reference as it corresponds to the expected macroscopic value of the sample and approximately matches the value minimising the work of each of the selected grains.

More specifically the activities of all other slip systems than $\mathrm{P}$ and $\mathrm{C}$ are kept constant while the sum of the activities of the $\mathrm{P}$ and $\mathrm{C}$ systems is distributed systematically from having the total combined activity on $\mathrm{P}$ with no $\mathrm{C}$ slip to the other extreme where the $\mathrm{C}$ system is the only active of the two. The resulting lattice rotations from this range of slip system combinations are calculated and applied to the initial orientation to produce the orientation spread. The simulations according to this scheme for the three reflections selected for each of the three grains are displayed in the right columns of Figure 5 to Figure 7. The corresponding experimental reflections are the left columns (central columns will be described below). For grain A in Figure 5 all three simulations extend along the same diagonal directions as the dark areas with most intensity in the experimental reflections. This is also the case for the two upper reflections for grain B in Figure 6 and the upper reflection for Grain C in Figure 7.

In order to better match the extension and intensity variations of the simulated reflections to the experimental data, the simulated reflections are refined by including only a subset of the simulated orientations and giving these different weights. This was done by trial-and-error and the best matches obtained are shown in the central columns of Figure 5 to Figure 7. The weights used are found in the histograms in Figure 8. Grains $\mathrm{A}$ and $\mathrm{C}$ are best matched by uniform weights for a subset of the initially tested orientation span. For Grain B the weighting is less uniform. In all cases the refined simulated reflections are in much better agreement with the experiment. In particular the refined reflections are the parts of the initially simulated reflections that are in best agreement with the three reflections (one for grain $\mathrm{B}$ and two for grain $\mathrm{C}$ ), which were less well represented in the first simulation. The magnitudes of the orientation spread originating from the determined P-C variations are $3.5^{\circ}$ for grains $\mathrm{A}$ and $\mathrm{C}$ and $5.4^{\circ}$ for grain $\mathrm{B}$. As a consistency check it is noted that the distributions in Figure 8 agree well with an average of $\gamma_{c} /\left(\gamma_{p}+\gamma_{c}\right)$ of $45 \%$ for grain A, $43 \%$ for grain $\mathrm{B}$ and $33 \%$ for Grain $\mathrm{C}$ as also calculated for the CMS orientations in Table 4 for $\mathrm{R}=3$. The simulated distribution of P-C variations therefore matches not only the spread but also the mean rotation. The $\mathrm{P}-\mathrm{C}$ variation, however, differs from grain to grain. 
The simulations in Figure 5 to Figure 7 show the orientation and slip system variations in one layer covering the entire cross section of the grains in the $10 \mu \mathrm{m}$ high beam. As the grains were investigated in several layers along the tensile direction, similar investigations of the variations along the long dimension of the grains can be conducted. Figure 9 shows two experimental spots of grain B for three layers, covering a total distance of $50 \mu \mathrm{m}$ along the tensile direction. It is seen that the reflections spread out in qualitatively similar ways in all layers, but that the intensity distributions - and therefore also the slip distributions - change.

The good match for all three reflections for each grain is very strong evidence that the orientations predicted from the $\mathrm{P}-\mathrm{C}$ variation are correct. This conclusion is further strengthened by the fact that for virtually the same crystallographic grain orientation a total of five different hkl-families, including also different variants of each family, have been employed (see Table 1). The combined data therefore confirm P-C variations as the dominant origin of orientation spread and also demonstrate that the distribution of slip on these systems consistently varies between grains of similar orientation as well as within the same grain.

\section{Discussion}

\subsection{Methodology}

As mentioned in the introduction the 3DXRD set-up has been selected among the many versions of the technique optimized for special purposes. Some of these have recently been applied to problems closely related to the present study, i.e. the orientation spread and slip system differences within single grains of a polycrystal. A major parameter when selecting the set-up is the distance between the sample and the detector. Small distances (near-field detectors) have the advantage of good spatial resolution, whereas large distances (far-field detectors) provide good orientation resolution. Set-ups with only one detector, either near-field [11] or far-field [39], have been employed, whereas the present study employs both.

Reconstruction from near-field data only has resulted in detailed space-filling grain maps, including spatial information about the orientation spread within individual grains [11,40]. The method is especially well-suited for direct comparison with finite-element-based crystal plasticity simulations, focusing on the local effects of grain interaction, e.g. near grain boundaries or triple junctions.

Using only a far-field detector, Wong et al. [39] focused on modelling the effect of different grain shapes and different neighbouring grains on the orientation spread of a grain of a single specific orientation. Finite-element-based polycrystal plasticity simulations were conducted and an advanced virtual diffractometer was constructed for the forward modelling to simulate the appearance of the diffraction spots on the detector. For an applied strain of $0.5 \%$, a spread on the order of a degree in $\eta$ was observed in both experiment and simulation. This virtual diffractometer was also employed in studies of cyclic deformation [41]. Pagan and Miller [42] explored lattice curvature in single Si crystals through interpretation of intermediate-field data with a mosaic model. Through choice of a single slip orientation, these authors were able to identify lattice curvature following from spatial variation in single slip, as proposed by Nye [43]. This was achieved through a forward modelling approach that considered both the topology and lattice rotation available in the detector images.

The forward modelling approach is an attempt to bring insight into the selection of slip within individual grains of a polycrystal. As in the work of Pagan and Miller, a kinematic approach is 
adopted: on the basis of preferred slip systems following from a classical analysis, gradients in slip are represented in a forward model and compared to experiment. We view this kinematic approach as an important first step in providing insight needed to advance models for crystal plasticity. While the present work does not specifically address the spatial distribution of the differently oriented parts of the grain, simulations for the present case show that the effect of the grain diameter is negligible compared to the magnitude of the orientation spread after $9 \%$ elongation. The magnitude of the orientation spread is also the reason why each spot is presented as a function of $\eta$ and $\omega$ in the current study, instead of as a single detector image.

In the present study many grains were close in both orientation and position due to the strong texture of the sample. The use of both near-field and far-field detectors greatly facilitated correct indexing of these grains. The texture is the major reason why only about half of the grains could be monitored all the way to $9 \%$ elongation. On the other hand the strong texture was deliberately selected to enable comparison of grains with initially similar orientations. As the focus of the present study is to investigate the effect of the grain orientation itself, space-filling grain maps giving the shape of each grain and information about its neighbouring grains are deemed outside the scope, but will be the topic of future investigations.

\subsection{Slip system selection and distribution}

The specific crystallographic orientation investigated in the present study was selected because grains of that orientation exhibited a large rotation scatter which cannot be attributed to Taylor ambiguity. The present analysis shows that the CMS rotations of all three grains are consistent with activation of four slip systems with high Schmid factors, which are also among the systems predicted by the Taylor model. The intergranular rotation scatter is reproduced by variations in the relative activities of these four systems, whereas the dominant intragranular spread is attributed to relative variations of only the two most stressed systems (termed $\mathrm{P}$ and $\mathrm{C}$ ).

The corresponding intragranular strain differences from the P-C variation have also been calculated. The variations in the tensile elongation are within $\pm 3 \%$ of the nominal $9 \%$ elongation of the sample. The corresponding R-values span from 2.6 to 3.7 ( $\pm 16 \%$ in q). The shear strain variations extend over a larger range up to a maximum of about $30 \%$ of the nominal elongation. Note that these strain gradients are not to be taken as the full intragranular strain gradients as the contribution from the P-C systems may be compensated from variations in some of the other slip systems. In particular, the shear strain differences originating from the $\mathrm{P}$ and $\mathrm{CDC}$ systems as well as the $\mathrm{C}$ and CDP systems partially compensate each other, and variations on all four systems can therefore reduce the intragranular strain gradient substantially. Full strain compatibility may be obtained by additional variations on also systems $(10 \overline{1})[1 \overline{1} 1]$ and $(0 \overline{1} \overline{1})[1 \overline{1} 1]$, i.e. the same set of 6 slip systems that account for the Taylor ambiguity for the presently considered orientation.

Figure 10 shows simulated orientation spreads for a single spot of grain B with the most obvious alternatives to the P-C variation. For comparison the experimental spot and the orientation spread from the $\mathrm{P}-\mathrm{C}$ variation are repeated in Figure $10 \mathrm{a}-\mathrm{b}$. The orientation spread arising from variations in the CDP-CDC variations alone calculated as previously done for the $\mathrm{P}-\mathrm{C}$ variation is illustrated in Figure 10c. It is seen that the spot broadens in a direction perpendicular to the spot from the P-C variations. The CDP-CDC systems therefore do not account for the major directionality of the orientation spread but may contribute to the widening of the spot. 
Figure 10d shows the spot broadening corresponding to the Taylor ambiguity (note that as the Taylor model does not reproduce the CMS rotation, the spread from the ambiguity has been artificially centred on the final CMS orientation of grain B). The spot elongation is clearly in another direction than for the experimental spot and also different from the CDP-CDC variation. It is, however, interesting that the maximum orientation spread from the Taylor ambiguity $\left(2.7^{\circ}\right)$ is much smaller than the experimentally observed value of $5.4^{\circ}$, which is within the predicted bounds of the present $\mathrm{P}-\mathrm{C}$ variation. This is not surprising as the resulting rotation from multiple slip systems tends to be smaller than that from a single system.

In order to explore additional explanations for the intragranular orientation spread, Figure 10e shows the spot shape for variations in the activity of the single slip system from the $\{110\}<111\rangle$ family having the closest rotation axis to the $\mathrm{P}$ and $\mathrm{C}$ systems. Figure 10 f presents the spot shape if the grain elongates heterogeneously by slip differences involving the same relative activities on the active systems throughout the grain but with variations in the absolute activity. This corresponds to an orientation spread constituting a tail from the initial to the final CMS orientation. Neither Figure 10e nor Figure 10f agrees with the experimental spot. It is therefore concluded that only the P-C variation agrees with the experimental observations and as demonstrated in section 5 this good agreement holds both with respect to the major directionality and the magnitude of the orientation spread for all investigated spots. The directionality of the smaller experimental spot widening is hard to establish and, by contrast to the elongation, its origin cannot be unambiguously identified.

\subsection{Grain orientation vs. grain interaction}

Even though the three grains were deliberately selected to represent the full span of the intergranular scatter, their different behaviour can be explained by variations between the same four slip systems, which account for more than about $70 \%$ of the total slip, according to the present calculations irrespective of the R-value assumed. This shows that the grain interaction is not strong enough to completely alter the identity of the active systems from those dictated by the grain orientation. As ambiguity effects could not explain the established intergranular and intragranular variations, these must be attributed to grain interaction, which changes the relative activities of these systems. In particular, the variations in spot broadening between layers along the tensile axis as demonstrated for grain B in Figure 9 may be attributed to variations in the local grain interaction. Substantial orientation changes have previously been correlated with changes in the identity of the neighbouring grains along the length of a grain as observed by 3DEBSD [44].

This general conclusion is also in agreement with the findings in both body-centred [45-47] and face-centred [48-52] cubic materials of similar alignment of dislocation boundaries in grains of similar orientation. The similar alignment was further linked to similarities in the activated slip systems [53] and correlated with changes in the flow stress upon a strain path change [54,55]. It follows that the dislocations gliding on these systems should be those accumulating in the dislocation boundaries, which has also been confirmed [56-58]. The subdivision by these dislocation boundaries alone can, however, not explain the presently observed orientation spread as the mean misorientation angle across such boundaries is about $1.3^{\circ}$ in $10 \%$ deformed interstitialfree steel [59]. The presently characterised intragranular orientation spread extends over $3-5^{\circ}$. It therefore corresponds to the long-range orientation gradients generally observed by EBSD [60,61] and also obtained from finite-element-based [62,63] and fast-Fourier-transformation-based [64] crystal plasticity simulations. In particular, the $3-5^{\circ}$ intragranular orientation spread found in the present study compares with a $2-4^{\circ}$ value reported in the finite element study of misorientation 
evolution by Dawson et al. [62]. Note also that such simulations also predict variations in the CMS rotations of grains with initially similar orientation.

\section{Conclusions}

By means of 3DXRD three grains of initially close orientation and different rotation paths, representative of the scatter of all investigated grains with tensile axes near $\langle 522\rangle$, have been identified. This scatter cannot be attributed to Taylor ambiguity and the intergranular as well as the intragranular orientation spreads have been analysed in detail by crystal plasticity simulations. The main findings are:

- The set of most active slip systems in all three grains are the same and account for more than $70 \%$ of the total slip. These systems are among those predicted by the Taylor model and also have high Schmid factors.

- Variations in the relative slip activities of these systems consistently explain the different rotation paths of the three grains, even when allowing for local strain variations.

- The systems with the two highest Schmid factors are responsible for most of the orientation spread within each grain. The determined variations agree with both the major directionality and the magnitude of the orientation spread.

These findings lead to the conclusion that the crystallographic orientation of the grains controls the identity of the most active slip systems. The relative variations in the activity of these systems are too big to be explained by Taylor ambiguity effects and must be attributed to grain interactions.

\section{Acknowledgements}

The authors are grateful to Drs. Lawrence Margulies, Xiaoxu Huang and Henning F. Poulsen for participating in the synchrotron experiment, and to Drs. Søren Schmidt and Henning Osholm Sørensen for helpful discussions on the data analysis and representation. Drs. Oddershede and Winther acknowledge support from the Danish Independent Research Council | Technology and Production Sciences grant no. DFF - 1335-00220 within which parts of the project have been carried out. The Danish Independent Research Council | Natural Sciences is acknowledged for covering expenses in relation to the synchrotron experiment (through Danscatt). The European Synchrotron Radiation Facility is acknowledged for granting beamtime for the experiment.

\section{REFERENCES}

[1] D.B. Williams, C.B. Carter, Transmission Electron Microscopy, Plenum Press, New York, 1996.

[2] A. Schwartz, M. Kumar, D. Dield, B. Adams, eds., Electron Backscatter Diffraction in Materials Science, 1st ed., Kluwer Academic, New York, 2000.

[3] H.F. Poulsen, Three-Dimensional X-Ray Diffraction Microscopy. Mapping Polycrystals and Their Dynamics, Springer, Berlin, 2004.

[4] R. Barabash, G. Ice, eds., Strain and Dislocation Gradients from Diffraction, Imperial College Press, 2014. 
[5] J. Oddershede, S. Schmidt, H.F. Poulsen, L. Margulies, J. Wright, M. Moscicki, W. Reimers, G. Winther, Mater. Charact. 62 (2011) 651-660.

[6] J. Oddershede, B. Camin, S. Schmidt, L.P. Mikkelsen, H.O. Sørensen, U. Lienert, H.F. Poulsen, W. Reimers, Acta Mater. 60 (2012) 3570-3580.

[7] J.K. Edmiston, J. V Bernier, N.R. Barton, G.C. Johnson, Acta Crystallogr. A. 68 (2012) 1817.

[8] L. Margulies, G. Winther, H.F. Poulsen, Science 291 (2001) 2392-2394.

[9] H.F. Poulsen, L. Margulies, S. Schmidt, G. Winther, Acta Mater. 51 (2003) 3821-3830.

[10] G. Winther, L. Margulies, S. Schmidt, H.F. Poulsen, Acta Mater. 52 (2004) 2863-2872.

[11] S.F. Li, J. Lind, C.M. Hefferan, R. Pokharel, U. Lienert, A.D. Rollett, R.M. Suter, J. Appl. Crystallogr. 45 (2012) 1098-1108.

[12] S. Schmidt, S. Nielsen, C. Gundlach, L. Margulies, X. Huang, D. Juul Jensen, Science 305 (2004) 229-232.

[13] S.S. West, S. Schmidt, H.O. Sørensen, G. Winther, H.F. Poulsen, L. Margulies, C. Gundlach, D. Juul Jensen, Scr. Mater. 61 (2009) 875-878.

[14] C. Hefferan, J. Lind, S. Li, U. Lienert, A. Rollett, R. Suter, Acta Mater. 60 (2012) 43114318.

[15] S.E. Offerman, N.H. van Dijk, J. Sietsma, S. Grigull, E.M. Lauridsen, L. Margulies, H.F. Poulsen, M.T. Rekveldt, S. van der Zwaag, Science 298 (2002) 1003-5.

[16] S. Schmidt, U.L. Olsen, H.F. Poulsen, H.O. Sorensen, E.M. Lauridsen, L. Margulies, C. Maurice, D. Juul Jensen, Scr. Mater. 59 (2008) 491-494.

[17] B. Jakobsen, H.F. Poulsen, U. Lienert, J. Almer, S.D. Shastri, H.O. Sørensen, C. Gundlach, W. Pantleon, Science 312 (2006) 889-892.

[18] C. Wejdemann, H.F. Poulsen, U. Lienert, W. Pantleon, J. Microsc. 65 (2013) 35-43.

[19] G. Sachs, Z. Ver. Deu. Ing. 72 (1928) 734-736.

[20] G.I. Taylor, Proc. R. Soc. London A145 (1934) 362.

[21] J. Bishop, R. Hill, Philos. Mag. A 42 (1951) 1298-1308.

[22] P. Van Houtte, Int. J. Plast. 21 (2005) 589-624.

[23] M. Crumbach, G. Pomana, P. Wagner, G. Gottstein, in:, G. Gottstein, D. Molodov (Eds.), Recryst. Grain Growth, Vols 1 2, Springer-Verlag Berlin, Berlin, 2001, pp. 1053-1060. 
[24] R.A. Lebensohn, C. Tomé, Acta Metall. Mater. 41 (1993) 2611-2624.

[25] D.P. Mika, P.R. Dawson, Mater. Sci. Eng. A 257 (1998) 62-76.

[26] A.J. Beaudoin, P.R. Dawson, K.K. Mathur, U.F. Kocks, Int. J. Plast. 11 (1995) 501-521.

[27] F. Roters, P. Eisenlohr, L. Hantcherli, D.D. Tjahjanto, T.R. Bieler, D. Raabe, Acta Mater. 58 (2010) 1152-1211.

[28] R.A. Lebensohn, Acta Mater. 49 (2001) 2723-2737.

[29] O. Mathon, G. Aquilanti, G. Guilera, J.-C. Labiche, P. van der Linden, M. Newton, C. Ponchut, A. Trapananti, S. Pascarelli, AIP Conf. Proc. 879 (2007) 1242-1245.

[30] Fable, http://sourceforge.net/p/fable/wiki/Home/

[31] S. Schmidt, J. Appl. Crystallogr. 47 (2014) 276-284.

[32] J. Oddershede, S. Schmidt, H.F. Poulsen, H.O. Sørensen, J. Wright, W. Reimers, J. Appl. Crystallogr. 43 (2010) 539-549.

[33] L. Nervo, A. King, J.P. Wright, W. Ludwig, P. Reischig, J. Quinta da Fonseca, M. Preuss, J. Appl. Crystallogr. 47 (2014) 1402-1416.

[34] T. Mánik, B. Holmedal, Int. J. Plast. 55 (2014) 152-181.

[35] G. Winther, Acta Mater. 56 (2008) 1919-1932.

[36] G.B. Sarma, P.R. Dawson, Acta Mater. 44 (1996) 1937-1953.

[37] S. Li, B.R. Donohue, S.R. Kalidindi, Mater. Sci. Eng. A 480 (2008) 17-23.

[38] U. Lienert, M. Brandes, J. Bernier, J. Weiss, S. Shastri, M. Mills, M. Miller, Mater. Sci. Eng. A 524 (2009) 46-54.

[39] S.L. Wong, J.-S. Park, M.P. Miller, P.R. Dawson, Comput. Mater. Sci. 77 (2013) 456-466.

[40] R. Pokharel, J. Lind, A. Kanjarla, R. Lebensohn, S. Li, P. Kenesei, R. Suter, A.D. Rollett, Annu. Rev. Condens. Matter Phys. 5 (2014) 317-346.

[41] M. Obstalecki, S.L. Wong, P.R. Dawson, M.P. Miller, Acta Mater. 75 (2014) 259-272.

[42] D. Pagan, M. Miller, J. Appl. Crystallogr. 47 (2014) 887-898.

[43] J. Nye, Acta Metall. 1 (1953) 153-162.

[44] F.X. Lin, A. Godfrey, D. Juul Jensen, G. Winther, Mater. Charact. 61 (2010) 1203-1210. 
[45] B. Peeters, B. Bacroix, C. Teodosiu, P. Van Houtte, E. Aernoudt, Acta Mater. 49 (2001) 1621-1632.

[46] A. Haldar, X. Huang, T. Leffers, N. Hansen, R.K. Ray, Acta Mater. 52 (2004) 5405-5418.

[47] S. Wang, M.P. Wang, C. Chen, Z. Xiao, Y.L. Jia, Z. Li, Z.X. Wang, Mater. Charact. 91 (2014) 10-18.

[48] X. Huang, G. Winther, Philos. Mag. 87 (2007) 5189-5214.

[49] F.X. Lin, A. Godfrey, G. Winther, Scr. Mater. 61 (2009) 237-240.

[50] G.M. Le, A. Godfrey, C.S. Hong, X. Huang, G. Winther, Scr. Mater. 66 (2012) 359-362.

[51] A.S. Taylor, P. Cizek, P.D. Hodgson, Acta Mater. 60 (2012) 1548-1569.

[52] N. Hansen, X. Huang, G. Winther, Mater. Sci. Eng. A. 494 (2008) 61-67.

[53] G. Winther, X. Huang, Philos. Mag. 87 (2007) 5215-5235.

[54] G. Winther, Scr. Mater. 52 (2005) 995-1000.

[55] Z.J. Li, G. Winther, N. Hansen, Acta Mater. 54 (2006) 401-410.

[56] R.J. McCabe, A. Misra, T.E. Mitchell, Acta Mater. 52 (2004) 705-714.

[57] Y. Wei, A. Godfrey, W. Liu, Q. Liu, X. Huang, N. Hansen, G. Winther, Scr. Mater. 65 (2011) 355-358.

[58] C.S. Hong, X. Huang, G. Winther, Philos. Mag. 93 (2013) 3118-3141.

[59] B. Li, A. Godfrey, Q. Meng, Q. Liu, N. Hansen, Acta Mater. 52 (2004) 1069-1081.

[60] L. Delannay, O. V Mishin, D. Juul Jensen, P. Van Houtte, Acta Mater. 49 (2001) 2441-2451.

[61] R. Quey, D. Piot, J.H. Driver, Acta Mater. 58 (2010) 1629-1642.

[62] P.R. Dawson, D.P. Mika, N.R. Barton, Scr. Mater. 47 (2002) 713-717.

[63] R. Quey, P.R. Dawson, J.H. Driver, J. Mech. Phys. Solids 60 (2012) 509-524.

[64] R.A. Lebensohn, R. Brenner, O. Castelnau, A.D. Rollett, Acta Mater. 56 (2008) 3914-3926. 


\section{TABLES}

Table 1 Specifications of the selected reflections for the three grains

\begin{tabular}{|c|c|c|c|c|}
\hline Grain & hkl & $2 \theta\left[^{\circ}\right]$ & $\eta\left[^{\circ}\right]$ & $\omega\left[^{\circ}\right]$ \\
\hline \multirow[t]{3}{*}{$\bar{A}$} & $0-13$ & 11.3 & 17.5 & 15 \\
\hline & $-1-2-3$ & 13.4 & 242 & 16 \\
\hline & $-2-1-3$ & 13.4 & 242.5 & 8.5 \\
\hline \multirow[t]{3}{*}{ B } & $01-3$ & 11.3 & 225.3 & 11 \\
\hline & $12-3$ & 13.4 & 246.5 & -7 \\
\hline & $22-2$ & 12.4 & 266.5 & 1.5 \\
\hline \multirow[t]{3}{*}{$\mathrm{C}$} & $00-2$ & 7.1 & 214.5 & -10 \\
\hline & $-2-20$ & 10.1 & 304.7 & -0.3 \\
\hline & 213 & 13.4 & 69.7 & -6 \\
\hline
\end{tabular}


Table 2. Schmid factors for uniaxial tension

\begin{tabular}{lcccc}
\hline & $\mathrm{P}$ & $\mathrm{C}$ & $\mathrm{CDP}$ & $\mathrm{CDC}$ \\
& $(\mathbf{\mathbf { 0 }} \overline{\mathbf{1}} \overline{\mathbf{1}})[\mathbf{1 1} \overline{\mathbf{1}}]$ & $(\overline{\mathbf{1 0 1}})[\mathbf{1 1 1}]$ & $(\mathbf{1} \overline{\mathbf{1}})[\mathbf{1 1} \overline{\mathbf{1}}]$ & $(\mathbf{\mathbf { 1 }} \overline{\mathbf{1}})[\overline{\mathbf{1 1 1}}]$ \\
\hline Grain A & 0.45 & 0.44 & 0.24 & 0.23 \\
Grain B & 0.42 & 0.40 & 0.28 & 0.26 \\
Grain C & 0.44 & 0.35 & 0.32 & 0.23 \\
\hline
\end{tabular}

Table 3. Average slip system activities for grains A, B and C from standard Taylor model (in \% of total activity).

\begin{tabular}{lcccccc}
\hline & $\mathrm{P}$ & $\mathrm{C}$ & $\mathrm{CDP}$ & $\mathrm{CDC}$ & Total $\Sigma \gamma^{j}$ & $\Sigma \gamma^{i} /$ Total $^{*}$ \\
& $(\mathbf{0} \overline{\mathbf{1 1}})[\mathbf{1 1} \overline{\mathbf{1}}]$ & $(\overline{\mathbf{1 0 1}})[\mathbf{1 1 1}]$ & $(\mathbf{1} \overline{\mathbf{1}})[\mathbf{1 1} \overline{\mathbf{1}}]$ & $(\mathbf{1} \overline{\mathbf{1} 0})[\overline{\mathbf{1 1 1}}]$ & & \\
\hline $\mathrm{R}=1$ & & & & & & \\
Average & $25 \%$ & $15 \%$ & $26 \%$ & $28 \%$ & 3.04 & $94 \%$ \\
$\mathrm{R}=3$ & & & & & & \\
Average & $43 \%$ & $18 \%$ & $5 \%$ & $25 \%$ & 3.01 & $91 \%$ \\
$\mathrm{R}=\infty$ & & & & & & \\
Average & $42 \%$ & $33 \%$ & $0 \%$ & $2 \%$ & 3.18 & $77 \%$ \\
\hline
\end{tabular}

$*$ Total $\Sigma \gamma^{i}$ is the sum of all active systems, $\Sigma \gamma^{i}$ sums over P, C, CDP and CDC 
Table 4. Slip system activities calculated when including measured rotations (Eq. 1)

$\begin{array}{lllll}\text { C } & \text { CDP } & \text { CDC } & \text { Total } \Sigma \gamma^{j} & \Sigma \gamma^{i} / \text { Total* }\end{array}$

\section{$(\mathbf{0 1 \overline { 1 }})[\mathbf{1 1} \overline{1}] \quad(\overline{\mathbf{1 0 1}})[\mathbf{1 1 1}] \quad(\overline{\mathbf{1}} \overline{0})[\mathbf{1 1} \overline{1}] \quad(\overline{1} \overline{10})[\overline{\mathbf{1 1 1}}]$}

\begin{tabular}{|c|c|c|c|c|c|c|}
\hline \multicolumn{7}{|l|}{$R=1$} \\
\hline Grain A & $21 \%$ & $18 \%$ & $12 \%$ & $22 \%$ & 3.19 & $73 \%$ \\
\hline Grain B & $21 \%$ & $12 \%$ & $30 \%$ & $16 \%$ & 3.70 & $79 \%$ \\
\hline Grain C & $23 \%$ & $9 \%$ & $11 \%$ & $33 \%$ & 3.78 & $76 \%$ \\
\hline \multicolumn{7}{|l|}{$\mathbf{R}=\mathbf{3}$} \\
\hline Grain A & $33 \%$ & $27 \%$ & $1 \%$ & $17 \%$ & 3.01 & $75 \%$ \\
\hline Grain B & $28 \%$ & $21 \%$ & $24 \%$ & $7 \%$ & 3.75 & $80 \%$ \\
\hline Grain C & $32 \%$ & $16 \%$ & $2 \%$ & $25 \%$ & 3.74 & $78 \%$ \\
\hline \multicolumn{7}{|l|}{$\mathbf{R}=\infty$} \\
\hline Grain A & $30 \%$ & $32 \%$ & $0 \%$ & $10 \%$ & 3.34 & $74 \%$ \\
\hline Grain B & $34 \%$ & $26 \%$ & $14 \%$ & $0 \%$ & 3.98 & $74 \%$ \\
\hline Grain C & $30 \%$ & $20 \%$ & $0 \%$ & $16 \%$ & 4.24 & $66 \%$ \\
\hline
\end{tabular}




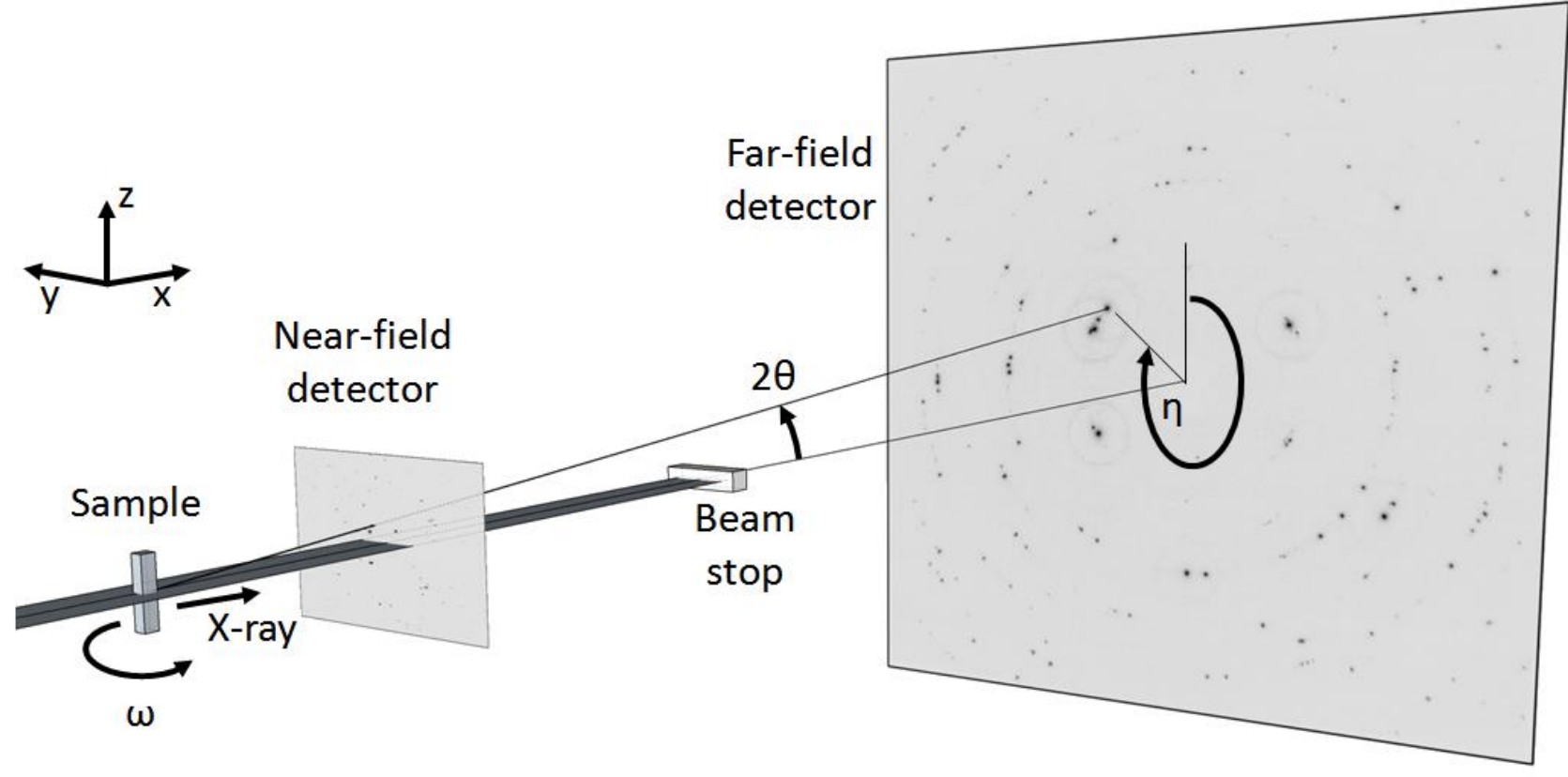

Figure 1. 3DXRD set-up with a far-field and a near-field detector (distances are not to scale). The angles $2 \theta, \eta$ and $\omega$ as well as the directions $x, y$ and $z$ are defined. The detectors show spots from the undeformed sample.
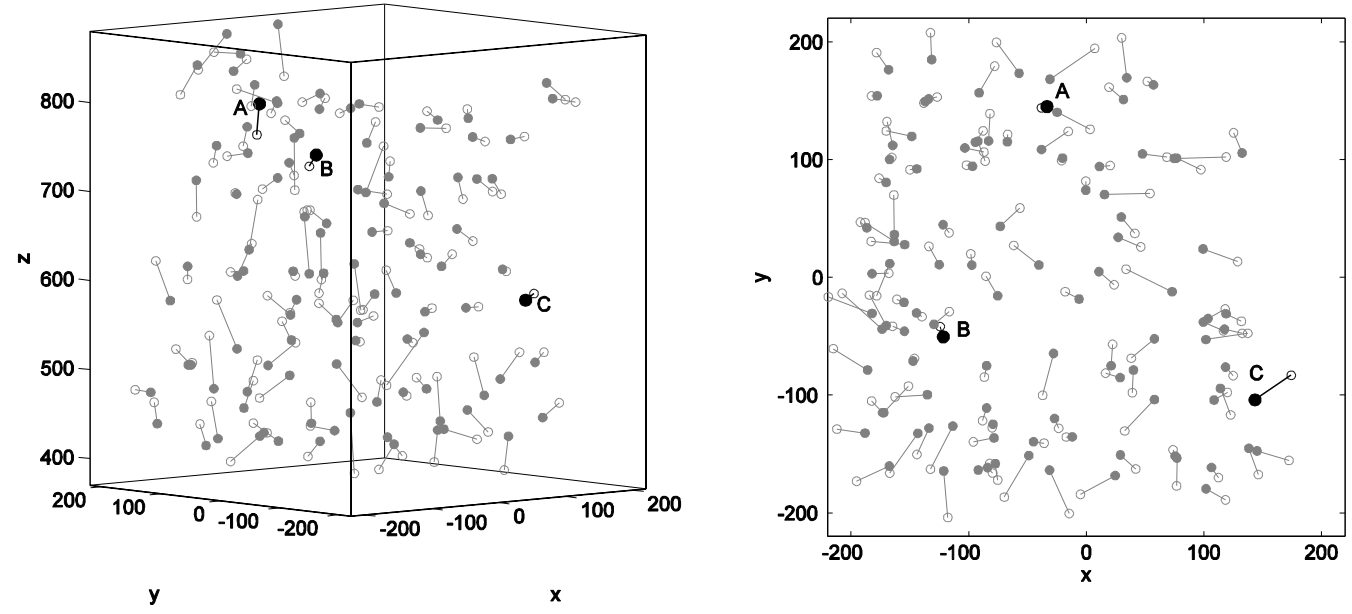

Figure 2. Positions and spatial translations of the center of mass for grains in the undeformed (open symbols) and 9\% deformed (solid symbols) polished sample with three grains selected for further studies marked: a) side view of sample and b) top view along the tensile axis. The distances on the axes are in micrometers. 

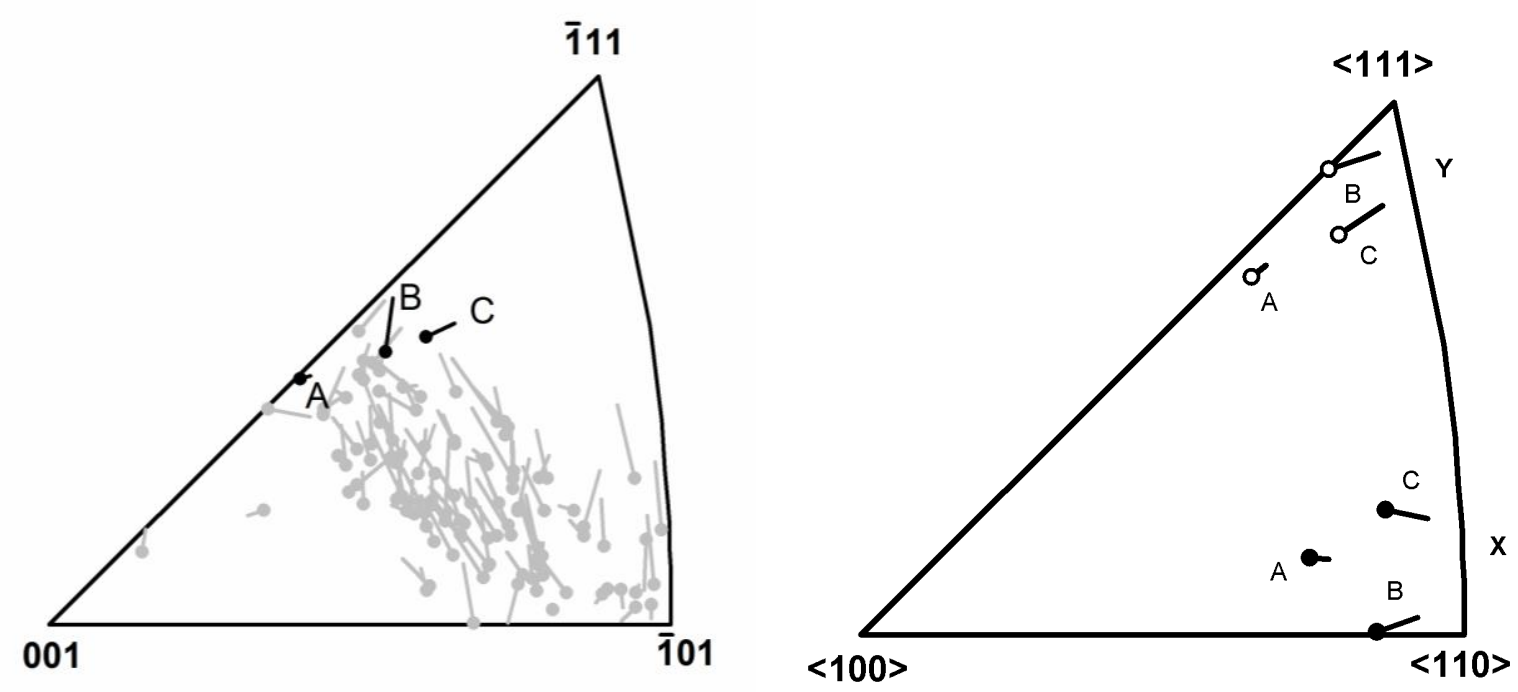

Figure 3. a) Lattice rotations of the tensile z-axis after $9 \%$ tensile deformation. The three selected grains are marked and b) shows the corresponding rotations of their $\mathrm{x}$ - and $\mathrm{y}$-directions with solid and open symbols, respectively.
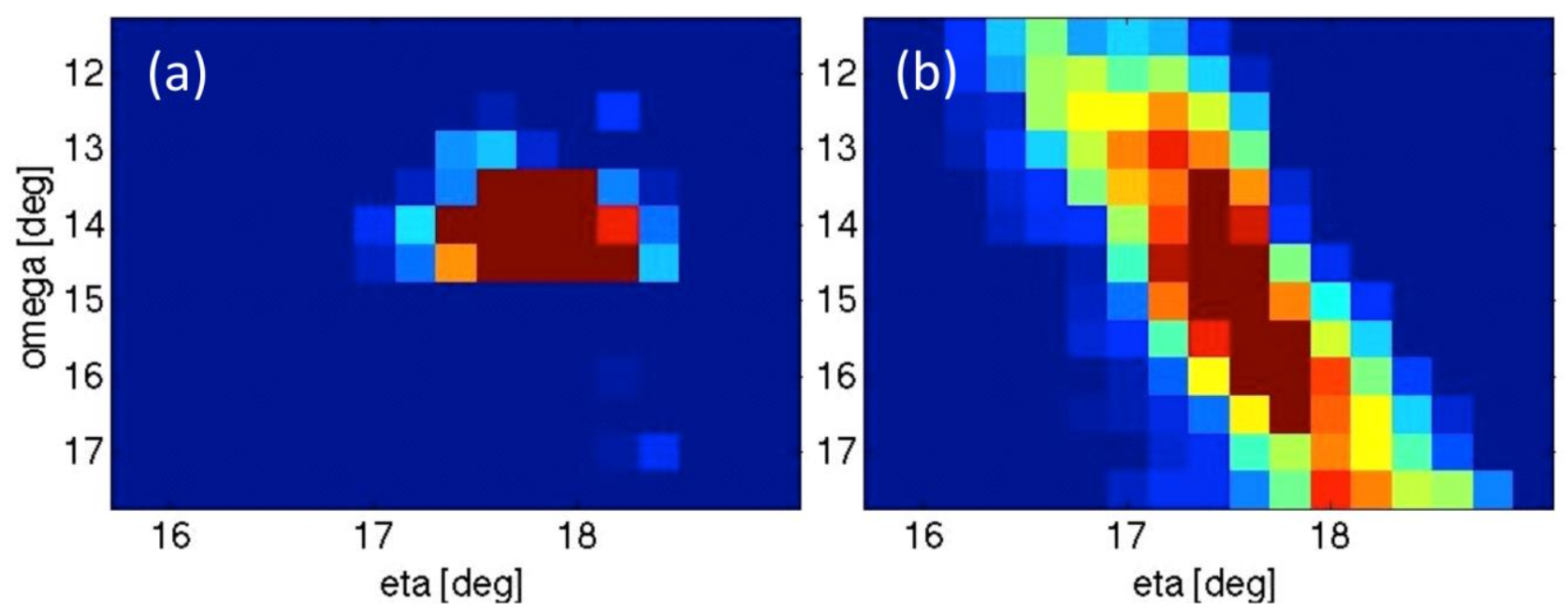

Figure 4. Reflection 0-13 of grain A a) before and b) after $9 \%$ tensile deformation. The intensity of the reflections is integrated over $2 \theta$ and presented as a function of the angles $\eta$ and $\omega$. The colour scale goes from the blue background value over green, yellow and red to brown at the maximum intensity. The scale is arbitrary and has been optimized for each reflection to give the best viewing conditions. 

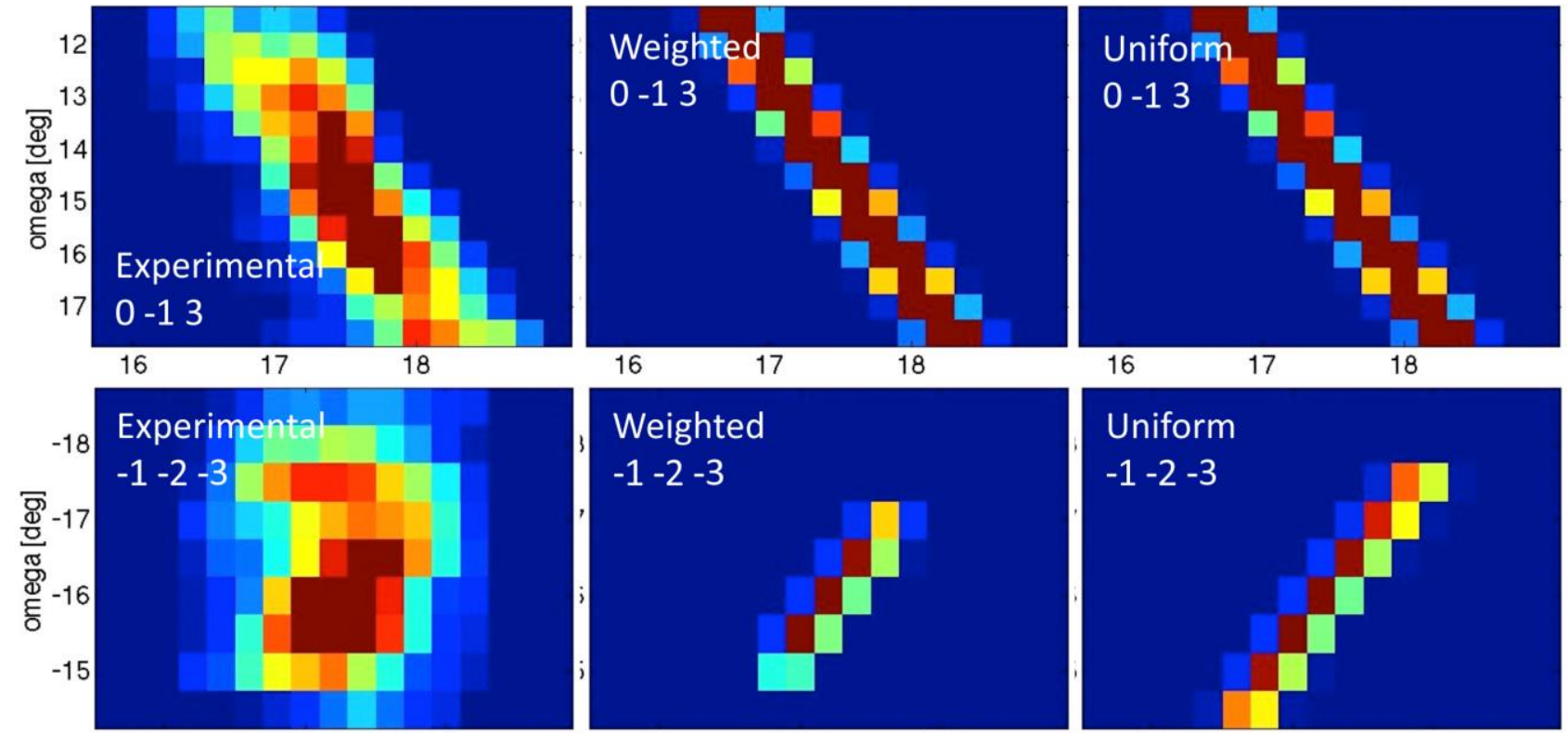

18
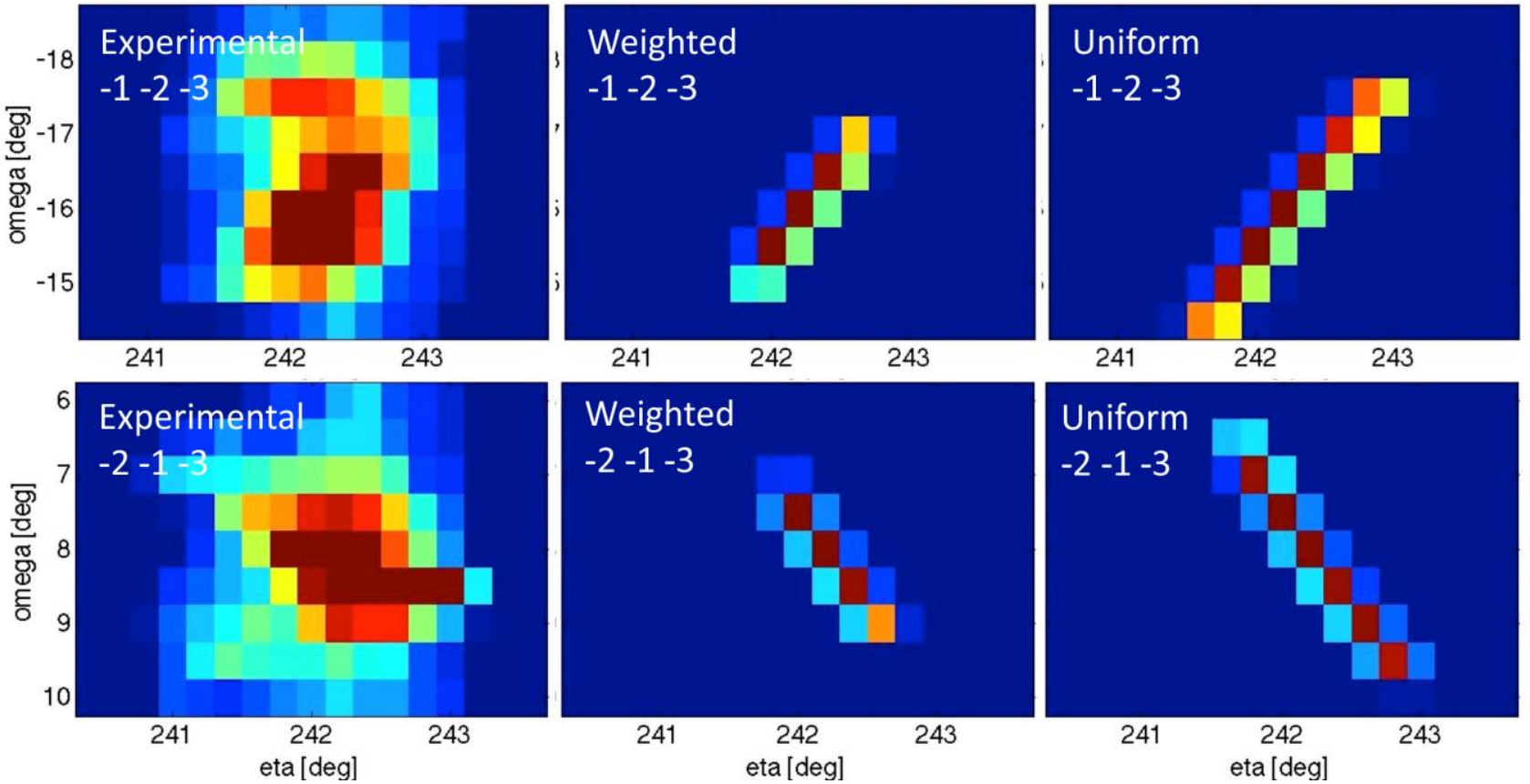

Figure 5. Left column: selected experimental reflections of grain A after $9 \%$ tensile deformation. Centre and Right: corresponding simulated spots according to the P-C hypothesis with different weighting (see section 5.2). 

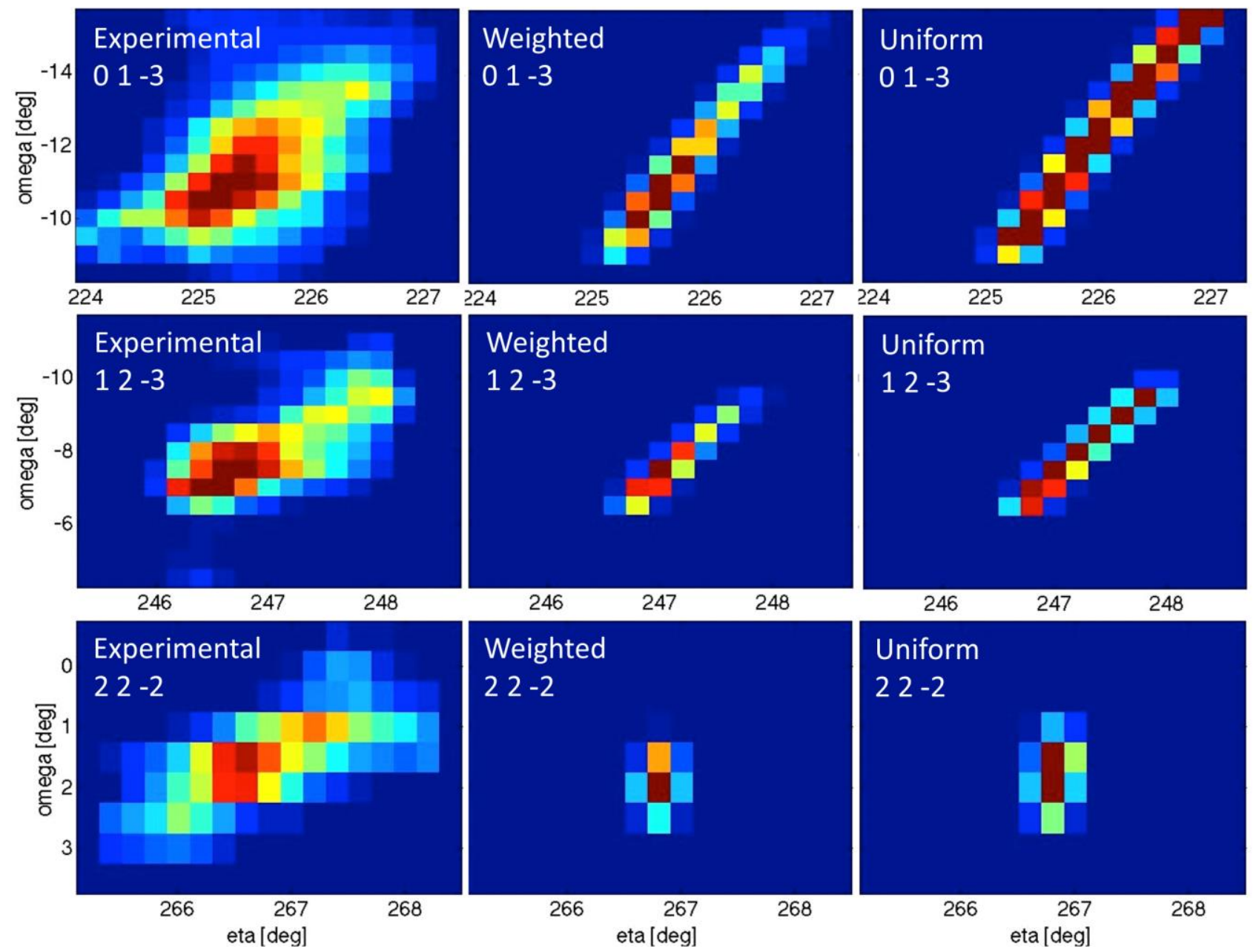

Figure 6. Left column: selected experimental reflections of grain B after $9 \%$ tensile deformation. Centre and Right: corresponding simulated spots according to the P-C hypothesis with different weighting (see section 5.2). 

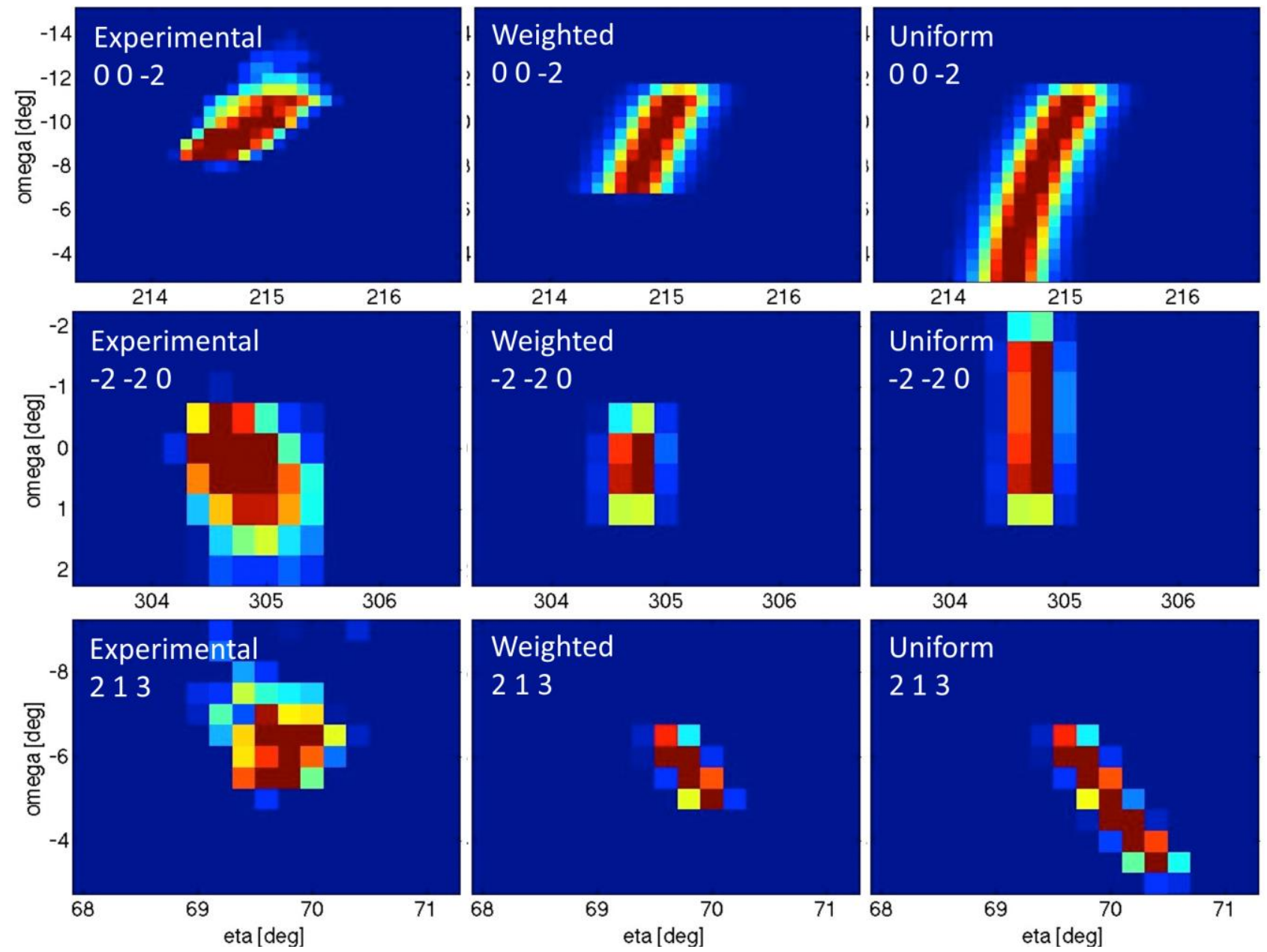

Figure 7. Left column: selected experimental reflections of grain $\mathrm{C}$ after $9 \%$ tensile deformation. Centre and Right: corresponding simulated spots according to the P-C hypothesis with different weighting (see section 5.2). 

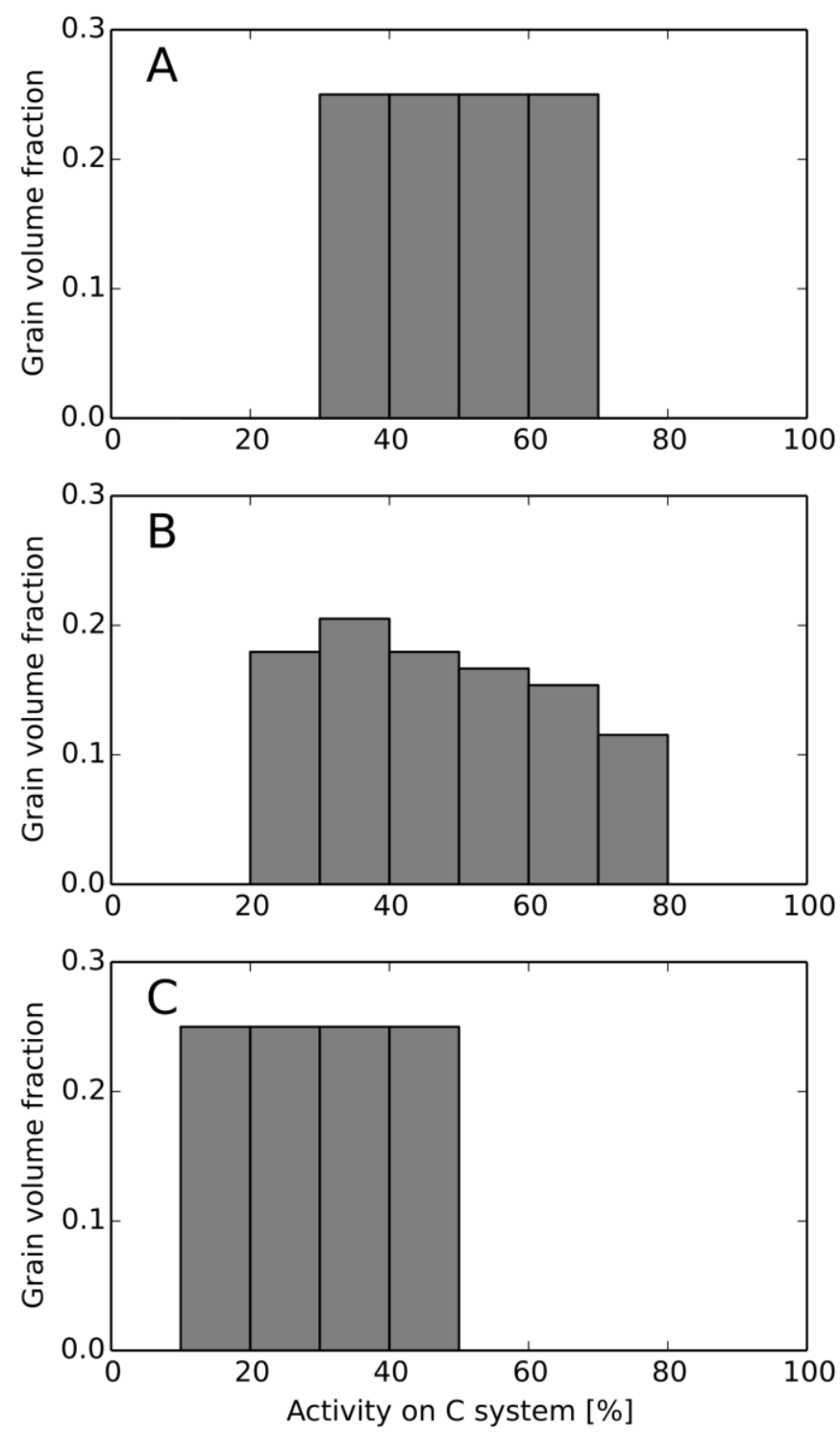

Figure 8. Weighted distribution of the slip activities of the $\mathrm{P}$ and $\mathrm{C}$ systems employed in the central columns of Figure 5 to Figure 7, matching the intensity distribution of the experimental reflections. 

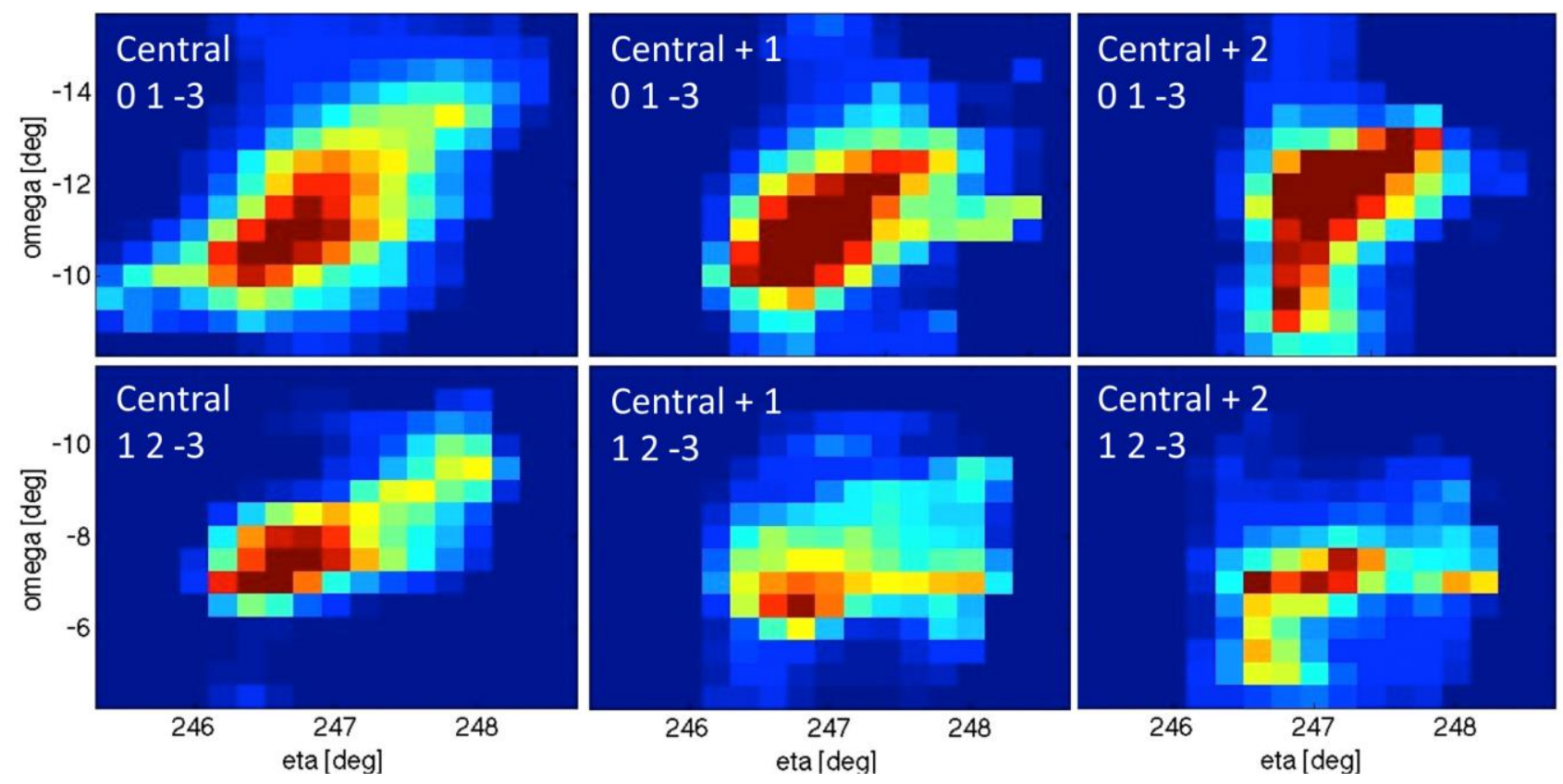

Figure 9. Experimental reflections $01-3$ and $12-3$ of grain B in the central layer of the grain and in the two subsequent layers.
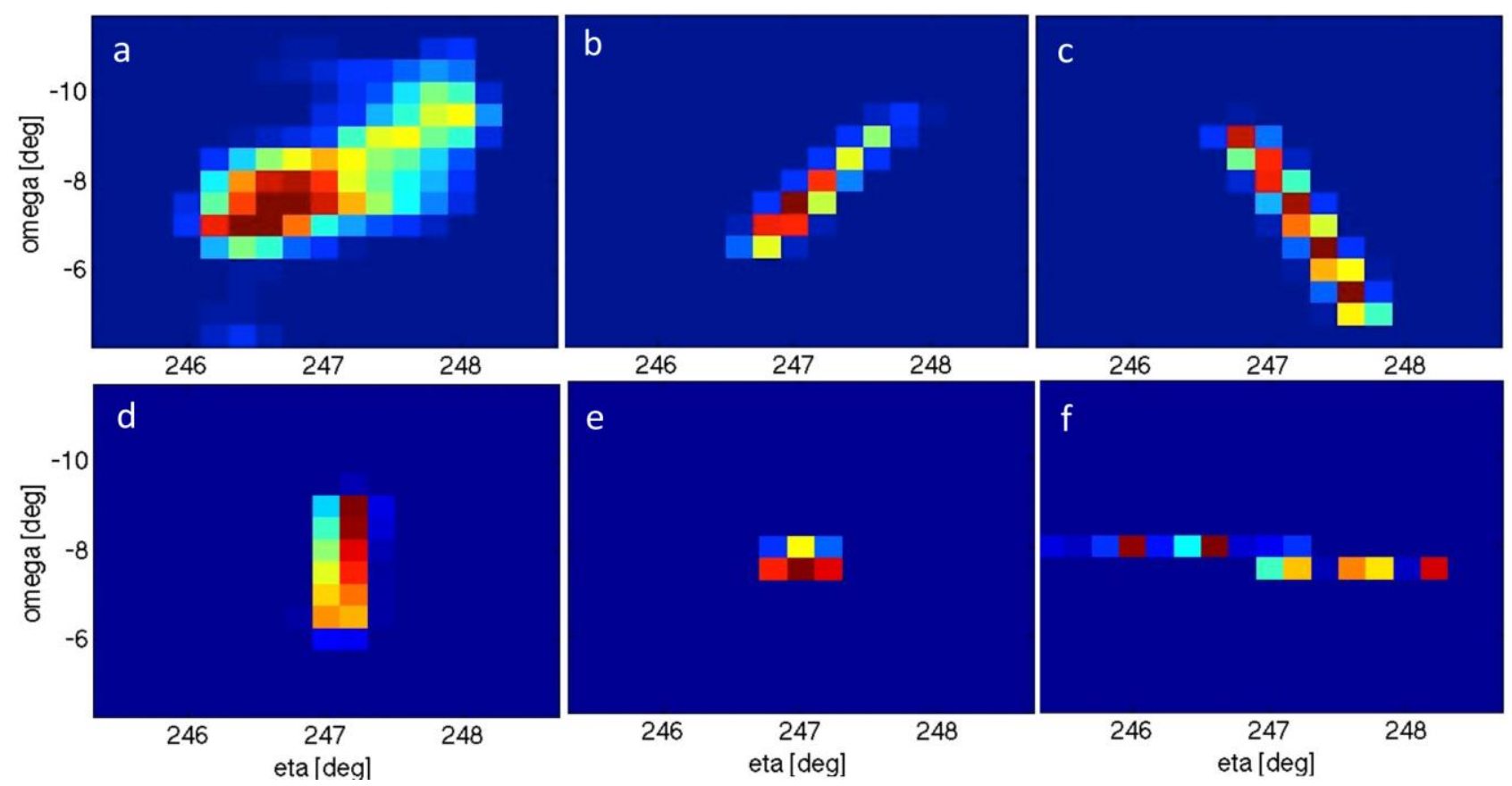

Figure 10. Reflection 12 -3 for grain B: a) experimental (from Figure 6), and simulated using b) P$\mathrm{C}$ variation (from Figure 6), c) CDP-CDC variation, d) Taylor ambiguity, e) closest other slip system, and f) an orientation tail (see section 6.2 for details). 